\title{
GEOKIMIA BATU PERMATA KRESNADANA PULAKI
}

\author{
I Wayan Karyasa ${ }^{1}$, I Gede Rasben Dantes², I Wayan Muderawan³ \\ I Wayan Rai ${ }^{4}$ \\ 1,3Jurusan Pendidikan Kimia, Universitas Pendidikan Ganesha \\ Singaraja, Indonesia \\ 2Jurusan Manajemen Informatika, Universitas Pendidikan Ganesha \\ Singaraja, Indonesia \\ 4Jurusan Pend. Jasmani, Kesehatan dan Rekreasi, Universitas Pendidikan Ganesha \\ Singaraja, Indonesia \\ E-mail: Karyasa.undiksha@gmail.com
}

\begin{abstract}
Abstrak
Batu permata Kresnadana Pulaki telah lama dikenal orang sebagai salah satu batu permata unik dari Kawasan Suci Pulaki, Kecamatan Gerokgak Kabupaten Buleleng, namun kajian ilmiah terhadap batu permata ini belum ada yang melaporkan. Tujuan penelitian ini adalah mengkarakterisasi tiga cuplikan batu permata "Kresnadana" yang diambil dari lokasi Pangkung Jahe yang merupakan bagian dari kawasan Pulaki. Metode difraksi sinar $X$ (XRD) dan fluorisensi sinar-X (XRF) digunakan untuk mengarakterisasi ketiga cuplikan batu permata tersebut. Hasil penelitian menunjukkan bahwa batu permata Pulaki tersusun fase utama kuarsa atau silika (lebih dari $50 \%$ ) dan oksida-oksida penyerta seperti $\mathrm{CaO}, \mathrm{Fe}_{2} \mathrm{O}_{3}$ dan $\mathrm{Al}_{2} \mathrm{O}_{3}$ serta unsur-unsur lainnya seperti $\mathrm{Ba}, \mathrm{Cu}, \mathrm{Zn}, \mathrm{Ni}, \mathrm{V}, \mathrm{Sr}$, dan $\mathrm{Zr}$. Variasi komposisi unsur-unsur mayor dan minor menyebabkan adanya variasi warna dan tampilannya.
\end{abstract}

Kata kunci: batu permata, difraksi, fluoresensi

\begin{abstract}
The gemmstone Kresnadana Pulaki has already wellknown as one of the unique gemmstone from the holy area of Pulaki, the District of Gerokgak, the Regency of Buleleng, however scientific studies on the gemmstone was not yet reported. The research was purposed to characterize three samples of gemmstone "Kresnadana" mined from the location called Pangkung Jahe, one part area of Pulaki. X-Ray Diffraction (XRD) and X-Ray Fluoresence (XRF) methods were used to characterize the gemmstone samples. The results of the current study show that the main phase of the three samples of gemmstone is quarts or silica (more than 50\%) and some complementary oxides such as $\mathrm{CaO}, \mathrm{Fe}_{2} \mathrm{O}_{3}$, and $\mathrm{Al}_{2} \mathrm{O}_{3}$ as well as other elements such as $\mathrm{Ba}, \mathrm{Cu}, \mathrm{Zn}, \mathrm{Ni}, \mathrm{V}, \mathrm{Sr}$, and $\mathrm{Zr}$. The variation of major as well as minor elements composition caused the color and appearance variation.
\end{abstract}

Keywords: gemmstone, diffraction, fluoresence 


\section{PENDAHULUAN}

Batu Permata Pulaki adalah sebutan batu permata yang diperoleh dari kawasan suci dan keramat Pulaki. Kawasan ini termasuk ke dalam wilayah adat Desa Pekraman Banyupoh dan wilayah administrasi Desa Banyupoh, Kecamatan Gerokgak, Kabupaten Buleleng. Kawasan Pulaki ini terdiri dari hamparan tanah subur yang 'nyegara gunung", bertepian pantai utara Bali dan di bagian barat, selatan dan timur dikelilingi perbukitan keramat Pulaki.

Batu permata Pulaki telah lama dikenal orang khususnya para penggemar batu permata. Salah satu batu permata terkenal dari kawasan Pulaki adalah batu permata Kresnadana dengan varian yang diberi nama Kresnadana Hitam Bercahaya Putih (batu sangat mulia dan langka) dan Kresnadana Tabur yaitu batu hijau hitam bertabur bintik-bintik keemasan, dan Kresnadana Berumbun yaitu batu hijau kehitaman yang bercampur dengan berbagai warna lainnya seperti merah, ungu, kuning, biru dan coklat. Batu permata lainnya yang juga terkenal dari kawasan Pulaki adalah permata yang diberi nama badar, bangsing dan nama-nama lain sesuai ciri-ciri khususnya atau keunikannya dan biasanya merujuk pada lokasi keramat di mana batuan yang mengnadung batu permata itu di temukan dalam kawasan Pulaki.

Berdasarkan cerita rakyat yang berkembang di Kawasan Pulaki, batu permata Kresnadana ditemukan dan diusahakan sebagai kerajinan batu permata pertama kali oleh Putu Dana (52 tahun, almarhum). Di balik cerita mistis dan religius tentang bagaimana menemukan lokasi batu permata tersebut di sela-sela perbukitan yang sangat tersembunyi dan sangat dirahasiakan, tersirat komitmen beliau untuk melestarikan dan mengendalikan eksploitasi berlebihan dari batu permata langka tersebut. Salah satu lokasi batu permata yang beliau ungkap adalah Pangkung Jahe (nama tempat yang merujuk pada tebing curam di perbukitan Pulaki) dengan luas areal batuan berpotensi mengandung batu permata sekitar 2 (dua) hektar. Lokasi ini sangat sulit dijangkau oleh orang biasa. Kali yang berhulu di Pangkung Jahe inilah biasanya sebagai lokasi para perajin batu permata di wilayah ini memperoleh bahan baku. Lokasi-lokasi lainnya yang tersebar di perbukitan Pulaki masih dirahasiakan dengan mitos-mitos keramat dan suci. Kearifan lokal in dirasakan cukup handal dalam melestarikan sumber daya alam batu permata ini dari eksploitasi yang berlebihan.

Nama-nama batu permata yang diperoleh di Kawasan Pulaki masih merujuk pada tampilan dan ciri-ciri khasnya, belum merujuk pada nama-nama ilmiah mineralmineral yang bersesuaian. Identifikasi ilmiah tentang batu permata Pulaki belum ada yang melaporkannya. Hal inilah yang mungkin menyebabkan batu permata ini tidak banyak dikenal secara internasional, kalah pamor dengan batu permata dari India, Srilangka, Thailand, Kamboja dan daerah lainnya. Oleh karena itu perlu dilakukan penelitian tentang jenis, struktur, dan komposisi batu mulia sekitar Pulaki. Penelitian itu secara khusus bertujuan mengkarakterisasi secara geokimia batu permata Kresnadana sebagai langkah awal untuk memberikan penjelasan ilmiah terhadap batu permata Pulaki.

\section{METODE PENELITIAN}

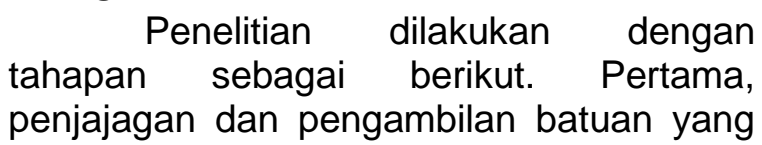
Jurnal Sains dan Teknologi $\mid 602$ 
mengandung batu mulia atau batu permata Pulaki di lokasi yang telah dikenali oleh penduduk setempat dengan nama Pangkung Jahe untuk memperoleh tiga jenis batuan yang mengandung batu permata yaitu Kresnadana Tabur (dengan kode cuplikan Pangkung Jahe 01), Kresnadana Berumbun (Pangkung Jahe 02), dan Kresnadana Polos (Pangkung Jahe 03). Kedua, batuan yang mengandung batu permata kemudian dipotong dan digosok atau dipolish untuk memperoleh batu permata yang diinginkan. Tahap ketiga, sebagian tiap-tiap batu permata diambil cuplikannya dan dibuat bubuk halus dari tiap cuplikan tersebut. Tahap keempat, tiap-tiap bubuk halus dianalisis kandungan unsur-unsurnya menggunakan metode instrumentasi XRF dan kandungan senyawa-senyawanya dengan metode $X R D$. Pada tahap ini data yang diperoleh awalnya adalah difraktogram XRF dan XRD untuk tiap cuplikan, yang selanjutnya dikonversi menjadi kandungan unsur-unsur dalam prosentase dan identifikasi senyawa kimia yang paling sesuai dengan bank data. Data dianalisis secara deskriftif dan komparatif.

\section{HASIL DAN PEMBAHASAN}

Hasil analisis XRD ditunjukkan dengan gambar-gambar difraktogram yang telah dicocokkan dengan data bank seperti yang ditunjukkan oleh Gambar 1 sampai dengan

\section{3}

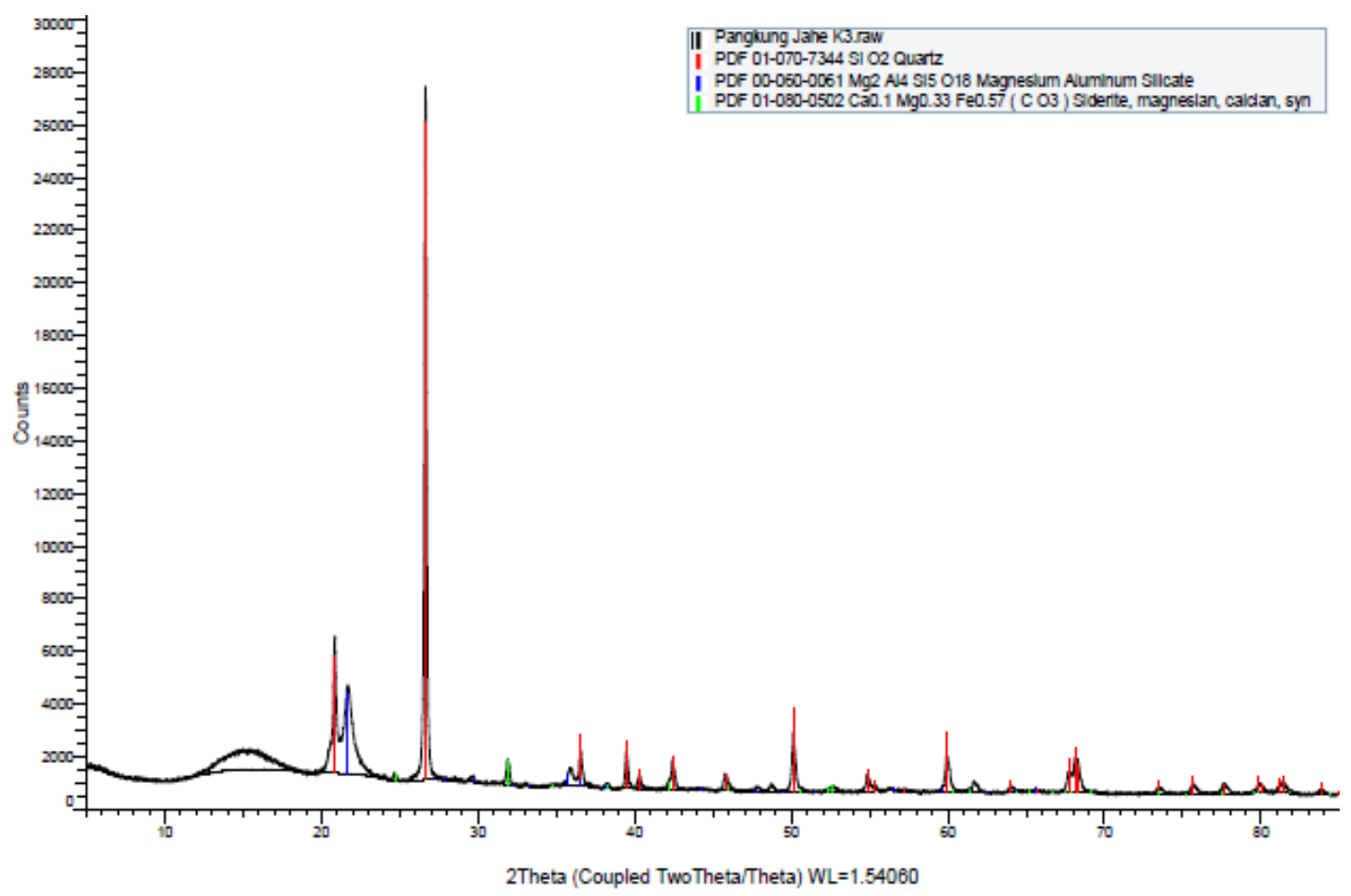

Gambar 1 Difraktogram Cuplikan Batu Pangkung Jahe 01 


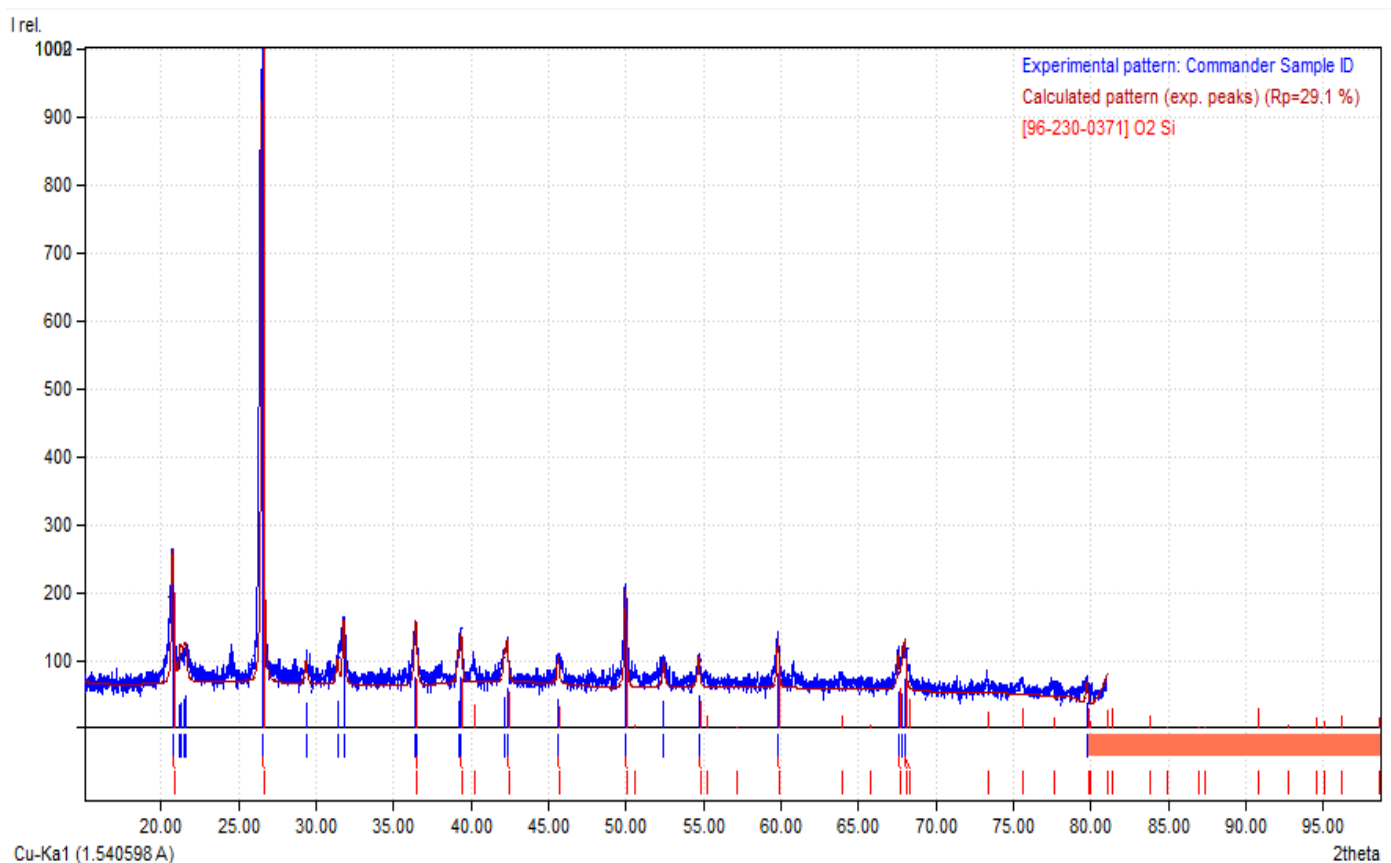

Gambar 2 Difraktogram Cuplikan Batu Pangkung Jahe 02

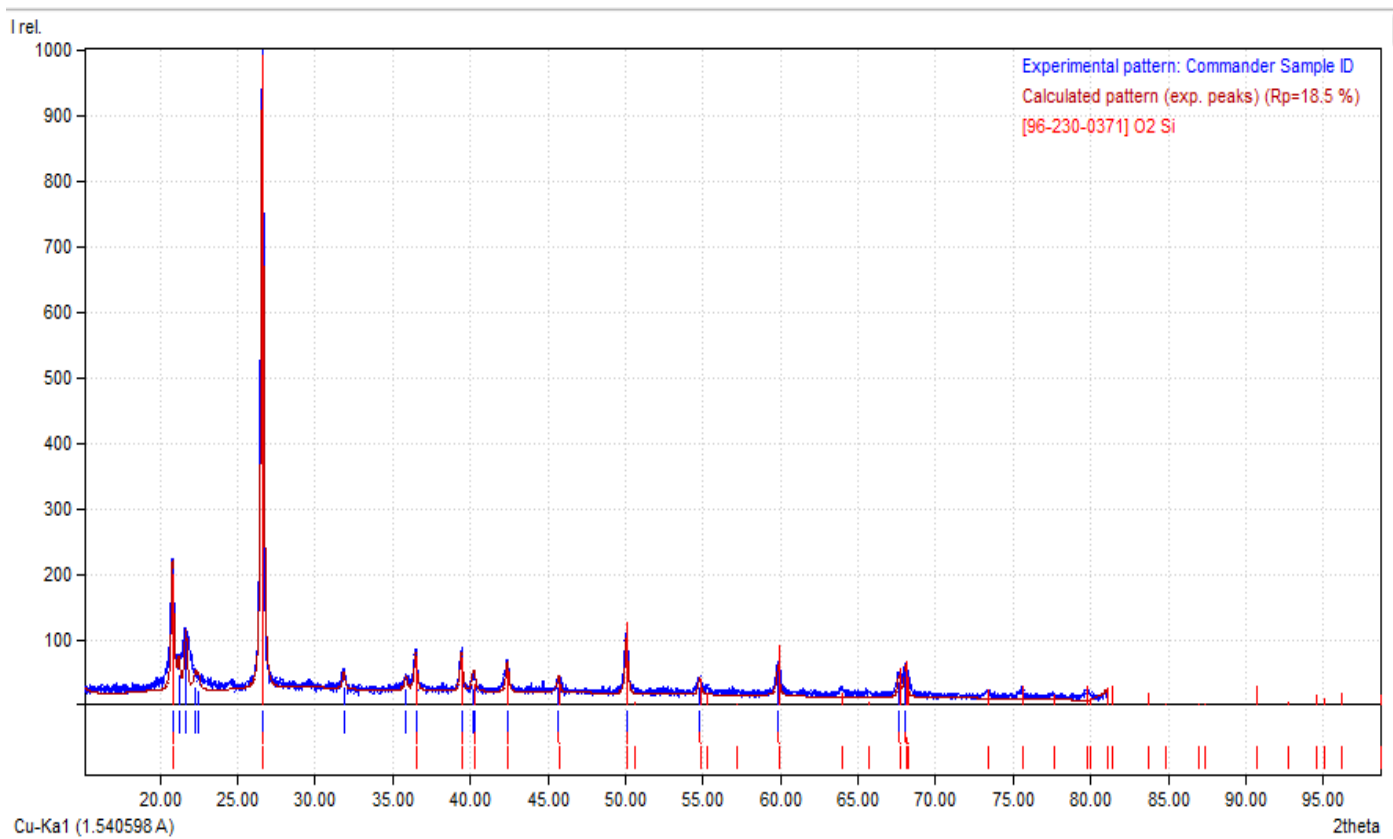

Gambar 4.3 Difraktogram Cuplikan Batu Pangkung Jahe 03 
Perbandingan kuantitatif kandungan oksida-oksida atau unsur-unsur mayor dalam prosentase (\%) dibuat grafik seperti pada Gambar 3. Gambar 3 menunjukkan bahwa ada 2 golongan batu permata Kresdana Pulaki kalau ditinjau dari kandungan silikanya yaitu: golongan $\mathrm{SiO}_{2}$ dengan kandungan silika di atas $75 \%$ dengan oksida-oksida penyerta yang kadarnya di bawah 5\% (Pangkung Jahe 03); dan golongan $\mathrm{SiO}_{2}-\mathrm{Fe}_{2} \mathrm{O}_{3}-\mathrm{CaO}$ dengan kandungan silika antara $51-75 \%$ dimana kandungan $\mathrm{Fe}_{2} \mathrm{O}_{3}$ dan $\mathrm{CaO}$ lebih dari 5\% (Pangkung Jahe 01 dan Pangkung Jahe 2).

Perbandingan kandungan (dalam pp) unsur-unsur minor (Gambar 4) umumnya logam-logam transisi dan logamlogam berat dapat menjelaskan batu permata yang berasal dari lokasi yang sama memiliki ciri warna dan tampilan kilap yang berbeda serta dipercaya masyarakat memiliki mitos-mitos khasiat atau manfaat yang unik. Batu mulia yang ditemukan di lokasi Pangkung Jahe Kawasan suci Pulaki memiliki tiga tampilan yang sangat terkenal di kawasan ini yaitu Batu Kresna Dana Tabur yang berwaran hijau kehitaman dan ada taburnya atau bercak-bercak logam mengkilap. Hal ini dapat dijelaskan, walaupun strukturnya kuarsa dengan kompoen utama $\mathrm{SiO}_{2}$ yang disertai $\mathrm{CaO}$, $\mathrm{Fe}_{2} \mathrm{O}_{3}$ dan $\mathrm{Al}_{2} \mathrm{O}_{3}$ tetapi mengandung barium (Ba) 700 ppm, tembaga (Cu) 351 ppm, stronsium (Sr) 101 ppm, vanadium (V) 94 ppm, seng (Zn) 93 ppm dan nikel (Ni) 89 ppm.

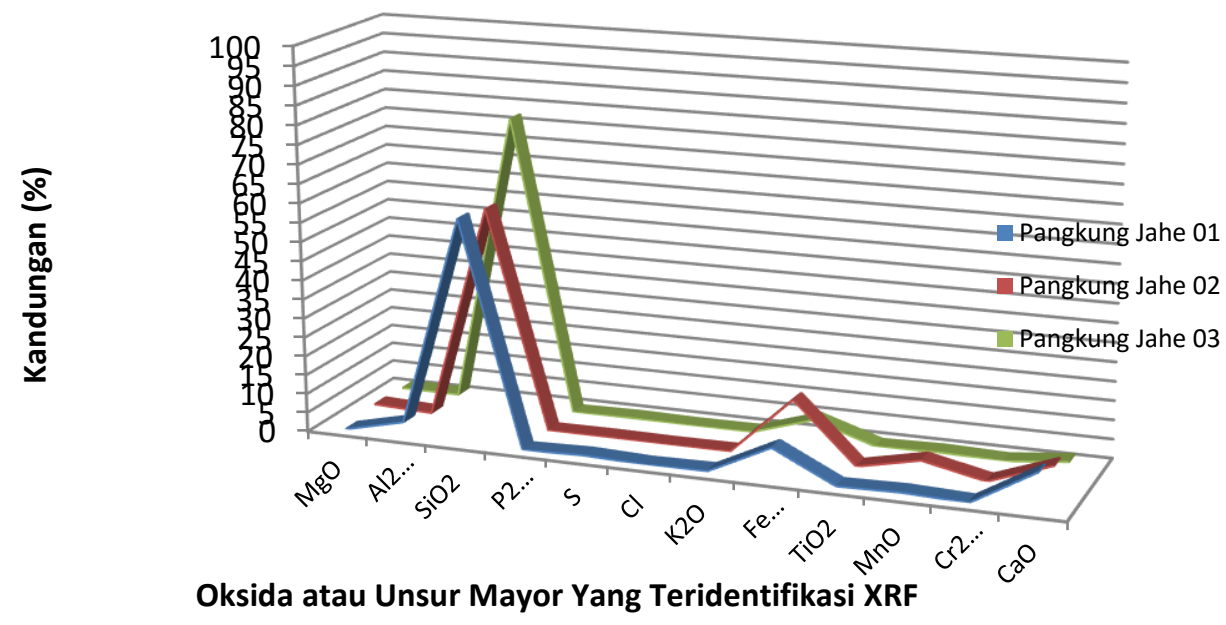

Gambar 3 Grafik Perbandingan Prosentase Oksida atau Unsur Mayor Hasil Analisis XRF Terhadap 3 Cuplikan Batu Permata Kresnadana Pulaki 


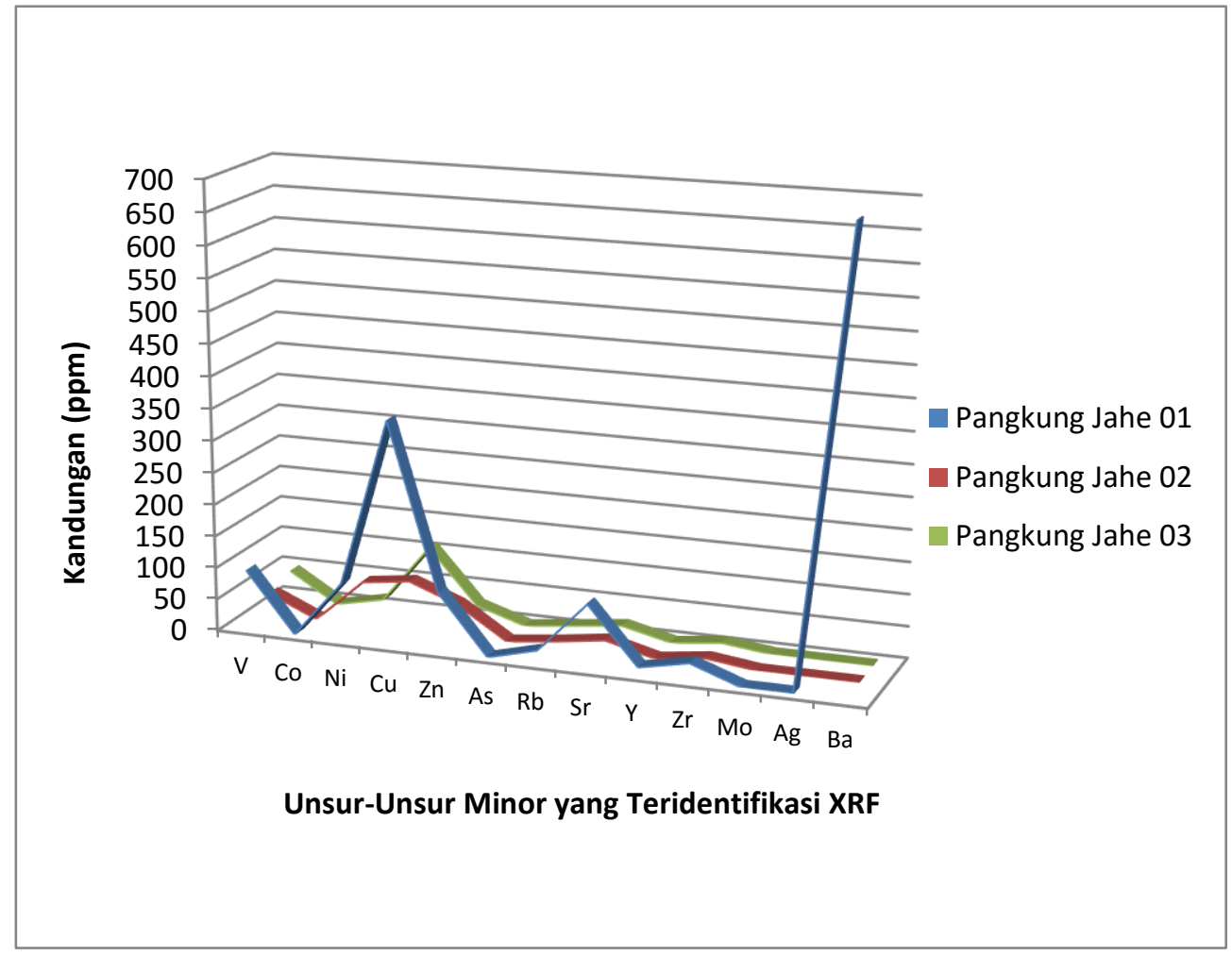

Gambar 4 Grafik Perbandingan Kandungan Unsur-Unsur Minor Hasil Analisis XRF Terhadap 3 Cuplikan Batu Permata Kresnadana Pulaki

\section{PENUTUP}

Hasil

karakterisasi

XRD

menunjukkan bahwa ketiga cuplikan batu permata Kresnadana Pulaki tersusun dari silika sebagai fase utamanya yang berarti sembilan sampel batu permata berbasis batu kuarsa. Hasil karakterisasi XRF mengkonfirmasi hasil XRD yaitu ketiga cuplikan mengandung oksida silikon yang besar (di atas 50\%) dan adanya variasi warna dan tampilan disebabkan oleh variasi kandungan unsur-unsur mayor dan minornya.

Karakterisasi lebih lanjut mengenai structur kristal penyusun batu permata Pulaki dan karaketerisasi fisik lainnya seperti uji kekerasan, kerapatan, indek bias, dan pengujian sifat-sifat khususnya seperti kemagnetan, daya hantar listrik, daya hantar panas, pengaruh sinar terhadap bidang permukaan dan daya kelarutan terhadap pelarut-pelarut kimiawi perlu dilakukan sehingga keunggulan batu permata Pulaki didukung oleh fakta dan kajian ilmiah yang memadai.

\section{UCAPAN TERIMA KASIH}

Tulisan ini didedikasikan kepada Putu Dana (almarhum) penemu dan pemberi nama batu permata Kresnadana Pulaki. Penghargaan diberikan kepada Kepala Desa Banyupoh dan Kelihan Adat Banyupoh yang mewilayahi Kawasan Suci Pulaki serta para pengerajin batu permata di Kawasan Pulaki atas berbagai informasi mengenai keberadaan dan eksistensi batu 
permata Pulaki. Ucapan terima kasih juga disampaikan kepada Direktorat Penelitian dan Pengabdian Kepada Masyarakat, Direktorat Jendral Pendidikan Tinggi Kementerian Pendidikan dan Kebudayaan Republik Indonesia atas dana IPTEK bagi Masyarakat tahun 2013 untuk eksplorasi,

\section{DAFTAR PUSTAKA}

Clarck, C. 1999. Gemmes Tropicales. Paris: Les editions du Pacifique. kajian aspek sosial serta pembinaan pengerajin batu permata di Kawasan Pulaki dan Lembaga Penelitian Universitas Pendidikan Ganesha atas dana Penelitian PUSLIT tahun anggaran 2014 untuk karakterisasi Batu Permata Pulaki.

Stephan, D. \& Aschberg, D. 2003. Das grosse Lexikon der Heilsteine. Augsburg: Weltbild Buchverlag. 